\title{
A highly conserved NB-LRR encoding gene cluster effective against Setosphaeria turcica in sorghum
}

\author{
Tom Martin $^{1 *}$, Moses Biruma ${ }^{2,3}$, Ingela Fridborg ${ }^{1}$, Patrick Okori ${ }^{2}$ and Christina Dixelius ${ }^{1}$
}

\begin{abstract}
Background: The fungal pathogen Setosphaeria turcica causes turcicum or northern leaf blight disease on maize, sorghum and related grasses. A prevalent foliar disease found worldwide where the two host crops, maize and sorghum are grown. The aim of the present study was to find genes controlling the host defense response to this devastating plant pathogen. A cDNA-AFLP approach was taken to identify candidate sequences, which functions were further validated via virus induced gene silencing (VIGS), and real-time PCR analysis. Phylogenetic analysis was performed to address evolutionary events.
\end{abstract}

Results: CDNA-AFLP analysis was run on susceptible and resistant sorghum and maize genotypes to identify resistance-related sequences. One CC-NB-LRR encoding gene GRMZM2G005347 was found among the up-regulated maize transcripts after fungal challenge. The new plant resistance gene was designated as St referring to $S$. turcica. Genome sequence comparison revealed that the CC-NB-LRR encoding St genes are located on chromosome 2 in maize, and on chromosome 5 in sorghum. The six St sorghum genes reside in three pairs in one locus. When the sorghum St genes were silenced via VIGS, the resistance was clearly compromised, an observation that was supported by real-time PCR. Database searches and phylogenetic analysis suggest that the St genes have a common ancestor present before the grass subfamily split 50-70 million years ago. Today, 6 genes are present in sorghum, 9 in rice and foxtail millet, respectively, 3 in maize and 4 in Brachypodium distachyon. The St gene homologs have all highly conserved sequences, and commonly reside as gene pairs in the grass genomes.

Conclusions: Resistance genes to S. turcica, with a CC-NB-LRR protein domain architecture, have been found in maize and sorghum. VIGS analysis revealed their importance in the surveillance to S. turcica in sorghum. The St genes are highly conserved in sorghum, rice, foxtail millet, maize and Brachypodium, suggesting an essential evolutionary function.

\section{Background}

The immune system has developed in a stepwise manner by progressive sophistication of basic functions that helped ancestral organisms to survive in their hostile environment. Recognition of pathogens in a species-specific way results in the generation of a very robust mode of surveillance system in plants. This form of protection termed resistance $(\mathrm{R})$ protein-mediated or effector-triggered immunity is induced when a plant encoded $R$ protein "perceives" the presence of a pathogen-derived effector molecule, represented by specific avirulence (Avr) gene products [1]. Following recognition of the pathogen, one

\footnotetext{
* Correspondence: Tom.Martin@slu.se

'SLU, Uppsala Biocenter, Dept. Plant Biology and Forest Genetics, Uppsala P. O. Box 7080, S-750 07, Uppsala, Sweden

Full list of author information is available at the end of the article
}

or more signal transduction pathways are induced in the host plant and these lead to the prevention of colonization by the pathogen.

The majority of characterized $\mathrm{R}$ proteins encode a nucleotide-binding site (NB) and leucine-rich repeats (LRR). NB-LRR-encoding genes make up one of the largest and most variable gene families found in plants, with most plant genomes containing several hundred family members [2-6]. The $\mathrm{N}$-terminal ends of $\mathrm{R}$-proteins are predominantly composed of a TIR (Toll/Interleukin-1 Receptor) homologous domain or form a coiled-coil (CC) motif. Monocots in particular, have numerous CC-NBLRR proteins in their genomes. Accumulating data suggest furthermore that $\mathrm{N}$ termini of R-proteins may interact with a range of pathogen-derived proteins. However, the LRR domain may determine the final outcome of this
C Biomed Central 
recognition, leading to downstream signaling and initiation of defense responses [7].

Many $R$-genes are located in clusters that either comprise several copies of homologous sequences arising from a single gene family or co-localized $R$-gene sequences derived from unrelated gene families $[8,9]$. This genomic make-up assists multiple proteins to become modified via various genic and intergenic processes enabling rapid evolution and adaptation to changes in a pathogen genome [10]. $R$-genes can also act in pairs $[11,12]$. The $R$-gene pairs can differ in genomic location and protein domain structure but also to their interaction with different pathogen isolates.

The heterothallic ascomycete Setosphaeria turcica (Luttrell) Leonard \& Suggs (anamorph: Exserohlium turcicum, former Helminthosporium turcicum) causes turcicum or northern leaf blight disease on maize. This fungal pathogen also attacks sorghum and related grass species, for example Johnson grass $[13,14]$. Turcicum leaf blight is one of the most prevalent foliar diseases in most maize-growing regions of the world. The disease causes periodic epidemics associated with significant yield losses, particularly under conditions of moderate temperature and high humidity [15-17]. Resistance to $S$. turcica has mainly been characterized in maize. S. turcica was earlier named Helminthosporium turcicum and resistance has hitherto been designated $H t$ and conferred by major race-specific genes $(H t 1, H t 2, H t 3$ or $H t N)$ or via partial resistance, reviewed by Welz and Geiger [18]. In our work we designate the new resistance genes as $S t$ referring to Setosphaeria turcica.

Maize and sorghum are the most important staple cereals for sub-Saharan Africa (SSA). While maize is an introduced crop [19], sorghum is believed to have been domesticated in SSA particularly in the Nile basin or Ethiopia, as recently as 1000 BC [20]. Sorghum like many other crop species experience large problems with plant pathogens, particularly fungal diseases. Turcicum leaf blight incited by S. turcica is one main problem [21]. This disease has been considered as of minor importance in Uganda until 1988 when it caused extensive yield losses on maize [22]. By introducing improved resistance in new varieties the threat posed by the disease was subsequently reduced. Severe and sporadic outbreaks of turcicum leaf blight have now reappeared in East Africa [23-25]. A change in the S. turcica population has been suggested to be the main cause of this shift in disease pattern. In order to detect potential new changes of the $S$. turcica pathogen and the turcicum leaf blight disease, a survey was undertaken in Uganda to examine the sorghum - S. turcica pathosystem in terms of disease severity and incidence, race patterns and new resistant resources [26]. It can be concluded from those studies that fungal isolates from sorghum could infect maize.
Upon cross inoculation on maize differential lines harboring different $H t$ genes, four $S$. turcica isolates were identified as race 1 , two as race 2 , and one isolate corresponded to race 0 and race 3 , respectively, whereas 10 isolates were unclassified. Highly resistant sorghum accessions originating from a regional collection were also identified.

In this work, we used cDNA-amplified fragment length polymorphism (AFLP) on resistant and susceptible maize and sorghum genotypes to identify differentially expressed genes, when challenged with S. turcica. This was followed by functional assessment of selected gene candidates by virus-induced gene silencing (VIGS) using a Brome mosaic virus vector. We found one $R$-gene cluster, containing six CC-NB-LRR encoding genes residing as three pairs in the sorghum genome, of importance for defense to S. turcica. Genome data further showed that the St genes are highly conserved within monocots.

\section{Results}

Identification of an up-regulated $R$-gene family in maize and sorghum in response to $S$. turcica inoculation

In order to identify important defense genes to $S$. turcica, cDNA-AFLP analysis was carried out on susceptible (S) and resistant (R) sorghum and maize genotypes following fungal infection. In our case, the Ugandan sorghum genotypes GA06/18 (R) and Sila (S) and the maize A619Ht1 (R) and A619 (S) lines were used. The sorghum material had earlier been evaluated on various agronomical traits including important fungal diseases. Apart from S. turcica responses, GA06/18 was found to be susceptible to Cercospora sorghi, and Colletotrichum sublineolum, whereas Sila was susceptible to C. sorghi and resistant to C. sublineolum.

In total, approximately 3000 transcript-derived fragments were monitored ranging from 50 to $600 \mathrm{bp}$ in size using different primer combinations (Additional file 1). Unique, up- or down-regulated transcripts in the resistant genotypes compared to the susceptible, sampled at 24, 48 and 72 hours post inoculation (hpi) were excised, amplified, sequenced and analyzed for putative function. The final transcript-set comprised of 68 sorghum and 82 maize gene candidates. Among these genes, 11 and 13, respectively, were putative stress-related according to closest genes identified in other organisms using BLASTP.

One CC-NB-LRR encoding putative $R$-gene (GRMZM2G005347), a member of a homologous gene pair with GRMZM2G005452 in the same locus on chromosome 2 , and uniquely expressed in the resistant maize genotype, was further studied (Figure 1D). Genome analysis revealed presence of 6 homologous genes in sorghum (Figure 1A). These six genes were given the prefix $S t$ referring to $S$. turcica and designated St1A (Sb05g008280), St1B (Sb05g008140), St2A (Sb05g008350), St2B (Sb05g008030), 


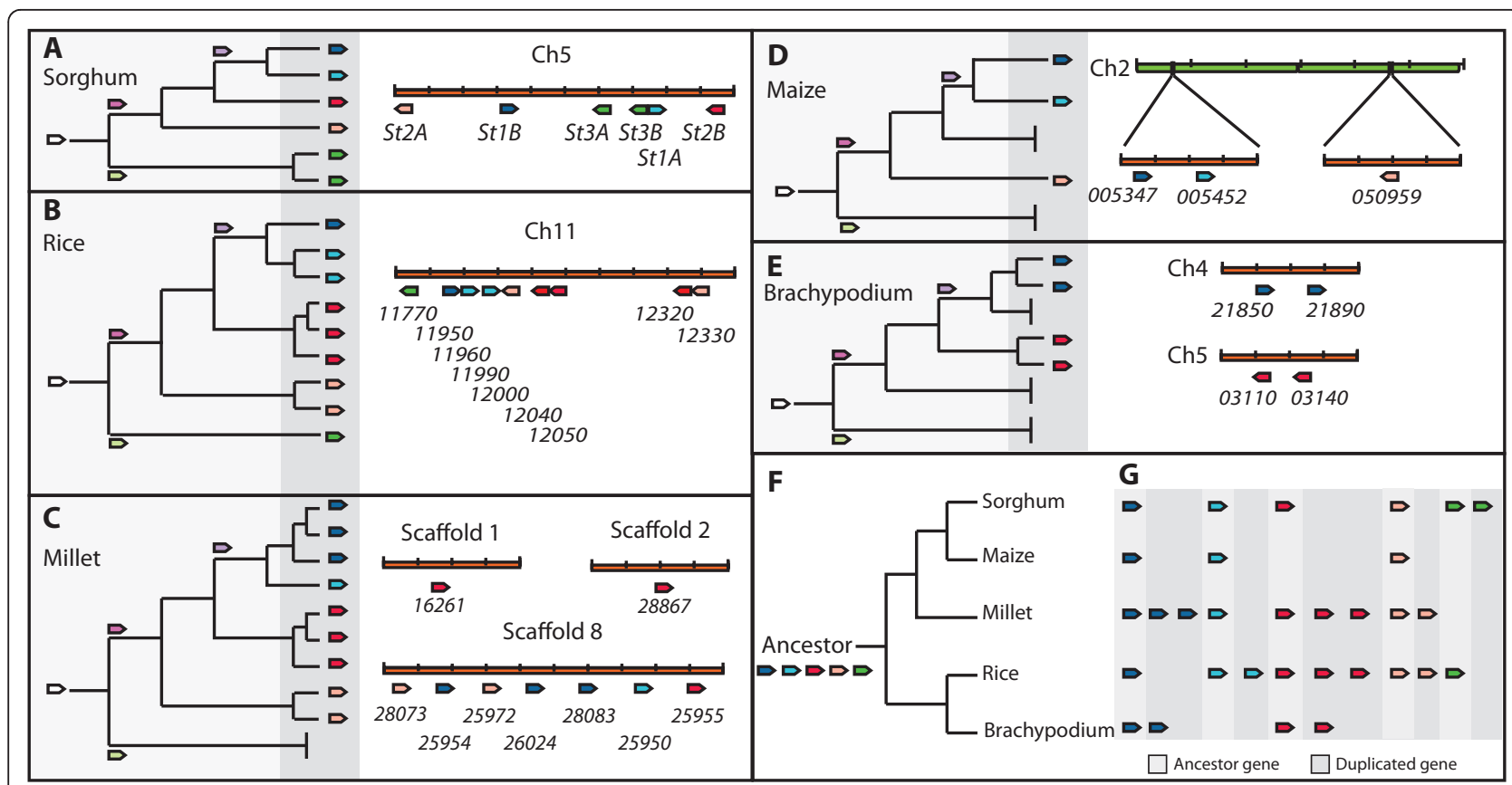

Figure 1 Evolution of $\boldsymbol{S t} \boldsymbol{R}$-gene cluster in monocots species. Chromosome location, duplication and ancestry of the St gene cluster in A. sorghum, B. millet, C. rice, D. maize, and E. Brachypodium. Events preceding, (light grey) and post speciation (dark grey) are shown. F. Proposed ancestral R-gene cluster composition using an ancestral tree of grass species adapted from Bowman et al. [55], and phylogenetic analysis of homologous genes in each species. Genes colored in relation to St genes as follows; St1 blue, St2 red, and St3 green. Gene information is listed in Additional file 2.

St3A (Sb05g008250), and St3B (Sb05g008270). Quantitative real-time PCR confirmed furthermore that five (St1A, $S t 2 A, S t 2 B, S t 3 A$ and $S t 3 B$ ) of the six St genes showed high relative transcript levels when the sorghum resistant GA06/18 plants were challenged with $S$. turcica (Figure 2). One gene, $S t 1 B$, was expressed to a much lower extent compared to the other $S t$ genes, outside the limit of detection. In Sila, only $S t 2 B$ and $S t 3 A$ showed a significant increase $(P<0.005)$ in expressions when challenged with S. turcica (Figure 2).

\section{The St genes are conserved among grasses}

The six $S t$ genes in sorghum form three gene pairs in a cluster on chromosome 5 and share a common ancestor (Figure 1; Additional file 2; Additional file 3). St gene orthologs were also found in clusters when searching the rice, maize, foxtail millet and Brachypodium genome databases. The $S t$ gene encoded proteins from the other grass species, grouped with the sorghum St proteins with high edge support (100) (Additional file 2). The rice genome contains orthologs of sorghum St1A, St1B, St $2 A, S t 2 B$ and an $S t 3$ gene (Figure 1A, B). This indicates that the ancestor of rice and sorghum likely had a copy of these genes. Sorghum St3A and $S t 3 B$ are likely a result of a more recent genome duplication event after the split between the rice and sorghum species (Figure $1 \mathrm{G})$. The rice genome also contains multiple copies of

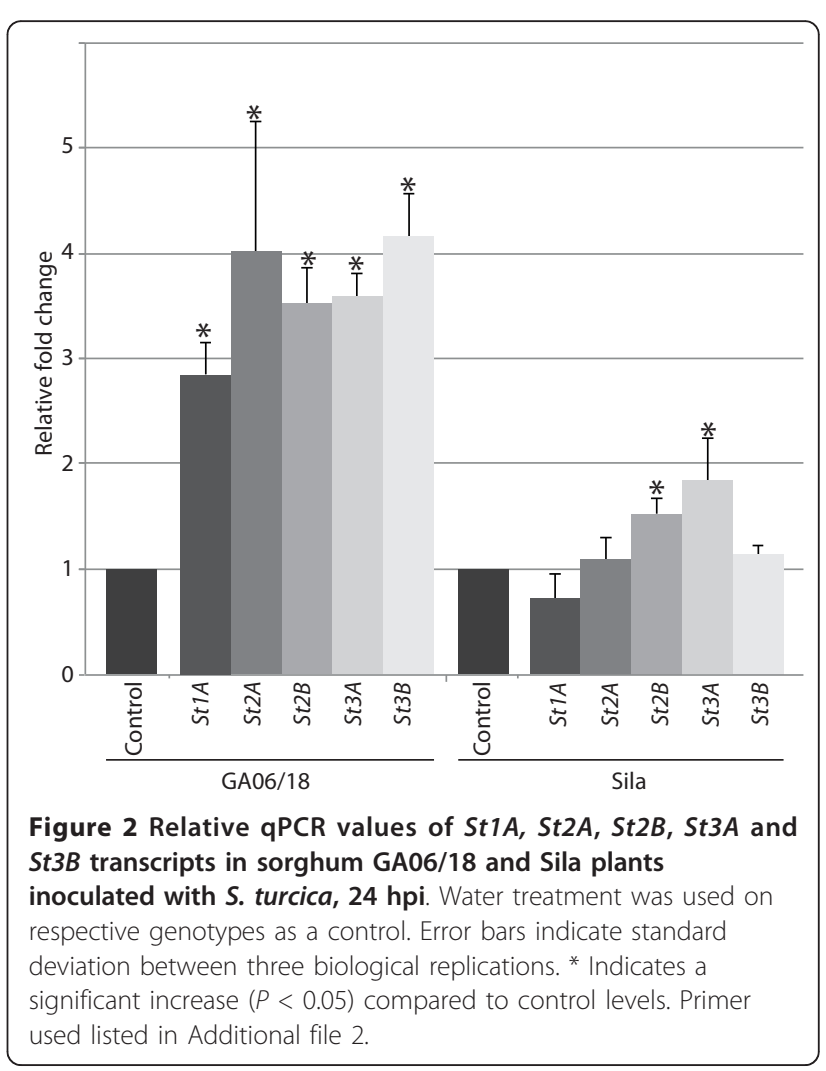


St1A, St $2 A$ and $S t 2 B$ orthologs, likely produced from gene duplications after the species split from sorghum. Likewise, the Setaria italica (foxtail millet) genome contains orthologs of $S t 1 A, S t 1 B$, St $2 A$ and $S t 2 B$, with seven of the nine genes found in a cluster within the same scaffold, as complete chromosome annotation have yet to be determined (Figure 1C). An St3 homolog was not found in millet. In addition to the maize gene pair identified in our cDNA-AFLP analysis, BLASTP and BLASTN searches revealed a third single gene homolog, GRMZM2G050959, St2A on maize chromosome 2 (Figure 1D). The model grass Brachypodium genome, on the other hand, has a gene pair orthologous to $S t 1 B$ on chromosome 4, and one to St $2 B$ on chromosome 5 , but lacks all other gene homologs (Figure 1E). The St gene cluster is maintained between sorghum, rice and possibly millet genomes but is smaller in maize and Brachypodium with $S t$ genes located across or on different chromosomes.

Sequence homology was also found between sorghum St proteins and Arabidopsis CC-NB-LRR encoding genes (Figure 3; Additional file 4). All six St proteins formed a cluster together with the CC rather than TIR domain containing $\mathrm{R}$ proteins from Arabidopsis indicating a closer evolutionary relationship as expected. The nearest related Arabidopsis gene is RPM1, a gene mediating resistance to Pseudomonas syringae isolates expressing the avrRpml or avrB genes [27].

\section{Adapting the VIGS system on sorghum}

Genetic transformation of sorghum and maize is possible but laborious and requires other genotypes than those used in this study to be successful $[28,29]$. Hence, our candidate genes were further studied using virus induced gene silencing (VIGS) using the Brome mosaic virus (BMV) system, previously used to silence genes in monocots [30]. VIGS was followed by fungal inoculation to assess the potential defense function of the St genes. In our hands, the VIGS procedure was not successful when applied to the A619Ht1 maize genotype. Because the St genes were up-regulated upon fungal inoculation with S. turcica in our sorghum GA06/18 genotype (Figure 2), we continued the studies on our sorghum materials.

Two VIGS constructs (1 and 2) with high identity to the $6 \mathrm{St}$ genes in sorghum were designed (Figure 4) including examination for their off-target gene silencing capacity. The highest non-St sorghum gene similarity belongs to a related $R$-gene pair, $S b 10 g 028720$ and $S b 10 g 028730$, located in a different subgroup upon phylogenetic analysis (Additional file 2), and used as a control for off-target gene silencing. The selected sequences were amplified and ligated into the third plasmid (pF13m) in the BMV system, and used to infect the sorghum plants.
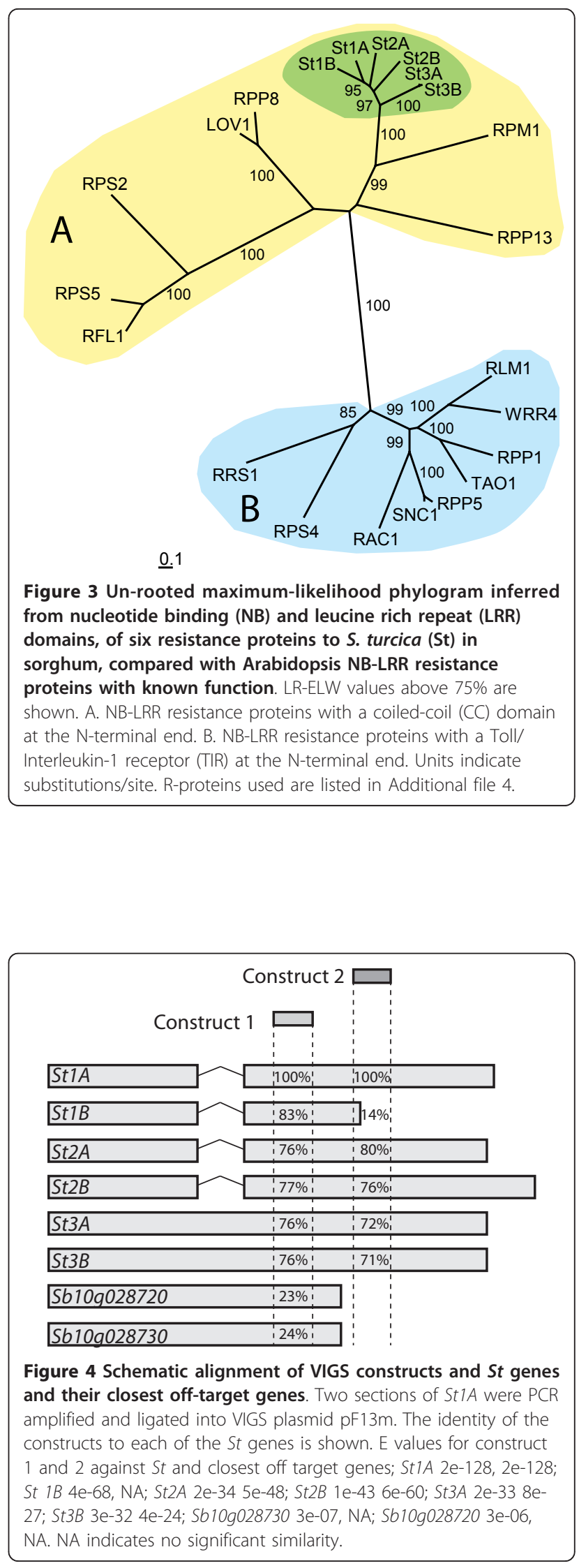
The VIGS procedure was first optimized. Sorghum seeds were surface sterilized before sowing to minimize additional stress by other microorganisms. mRNA was produced by in vitro transcription, added to inoculation buffer and rubbed directly onto the second leaf of three week old sorghum plants. No intermediate step involving barley as virus host was used. The virus spreads systemically throughout the plant with silencing greatest in the second and third leaves above the inoculation site and complete silencing rarely achieved [30]. Seven days post infection (dpi), light green colored streaks were visible on the third leaf, indicating viral symptoms and successful infection by the virus. In order to confirm onset of silencing quantitative real time-PCR was carried out on leaf samples from the VIGS treated plants (Figure 5). There was a significant decrease in the relative transcript levels in relation to control plants inoculated with empty plasmid suggesting a clear down-regulation of five of the six targeted genes, particularly by construct 1 , in both sorghum genotypes. Relative transcript levels of Sb10g028720 and Sb10g028730 were not influenced in VIGS treatments indicating no off-target silencing.

\section{Silencing of St genes increases S. turcica infection in the resistant and susceptible sorghum genotypes}

Fungal colonization and growth on plants inoculated with the different VIGS constructs compared with control material was carefully monitored. The different phenotypic observations are summarized in Figure 6; and Additional file 5. Fungal growth was further assessed by detaching infected leaves and placing them in a petri dish containing moist filter paper followed by incubation in the dark at $25^{\circ} \mathrm{C}$ for two days, as described by Levy [31]. The development of conidiophores protruding through leaf lesions followed by rapid asexual spore development indicated fungal colonization of the leaf material, and a susceptible phenotype.

A hypersensitive response (small dark/red spots) occurred at $2 \mathrm{dpi}$ on the resistant GA06/18 genotype upon fungal challenge while the plants treated with empty vector produced a somewhat delayed HR phenotype 3 dpi. When VIGS construct 1 was applied to GA06/18 plants prior to fungal inoculation, larger and more numerous lesions with chlorotic halos developed compared to the control plants. Disease lesions spread laterally along the leaf and fungal conidiophores and spores were produced under sporulating conditions. Similarly, when the effect of construct 2 was assayed, the disease lesions were seen $2 \mathrm{dpi}$ and spread laterally to form large lesions that produced large numbers of fungal spores. The disease lesions were larger than those induced by construct 1 , at $7 \mathrm{dpi}$. On the susceptible Sila plants clear disease symptoms, necrotic spots, and chlorotic halos around fungal appressoria were seen
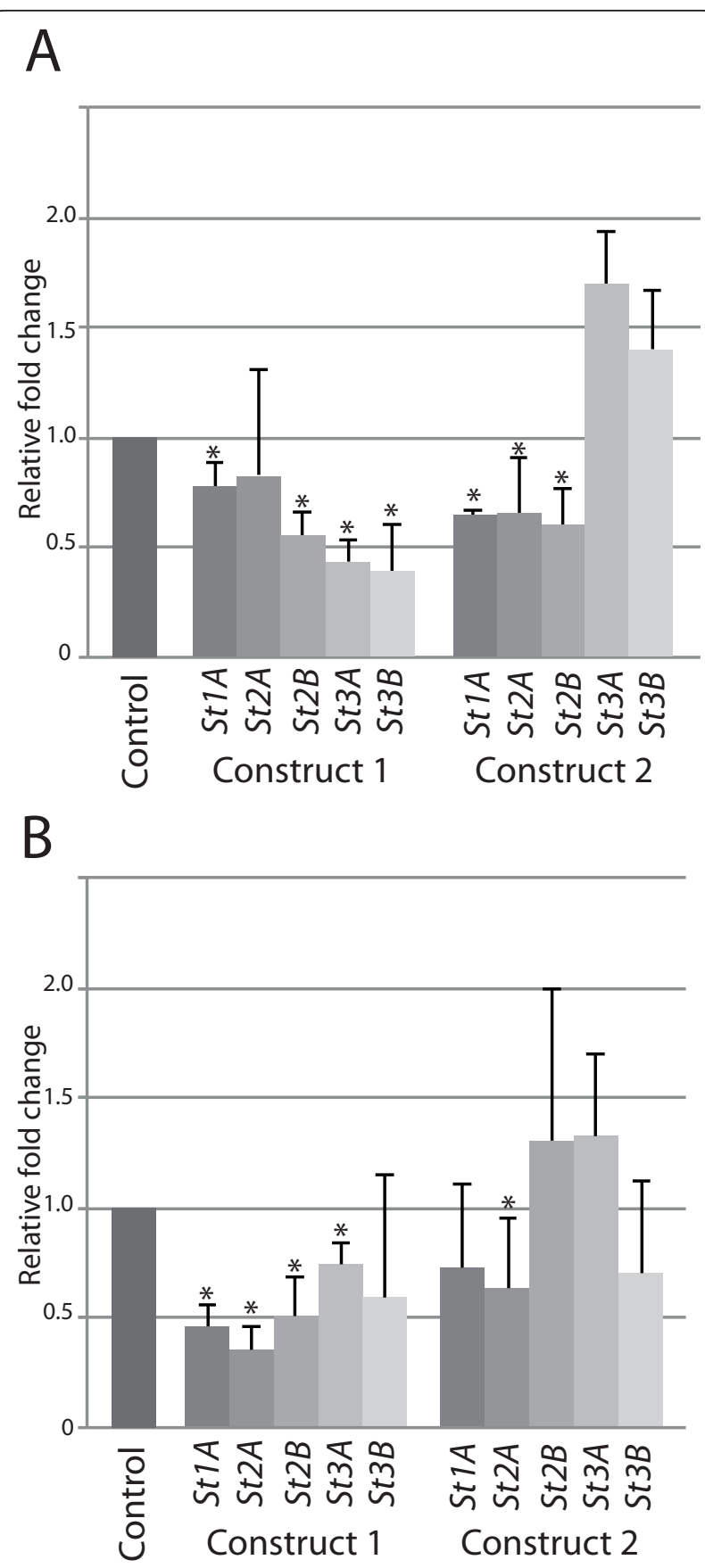

Figure 5 Relative qPCR values of St gene transcripts when inoculated with VIGS constructs 1 and 2 compared to empty vector control. Both GA06/18 (A) and Sila (B) genotypes showed down-regulation of five of the six St genes when inoculated with either one, or both of the constructs. Error bars indicate standard deviation between three biological replications. ${ }^{*}$ Indicates a significant decrease $(P<0.05)$ compared to control levels.

2 dpi. Large numbers of asexual fungal spores were produced on conidiophores protruding from necrotic lesions. When Sila plants were inoculated with the empty VIGS vector, prior to fungal inoculation, similar 


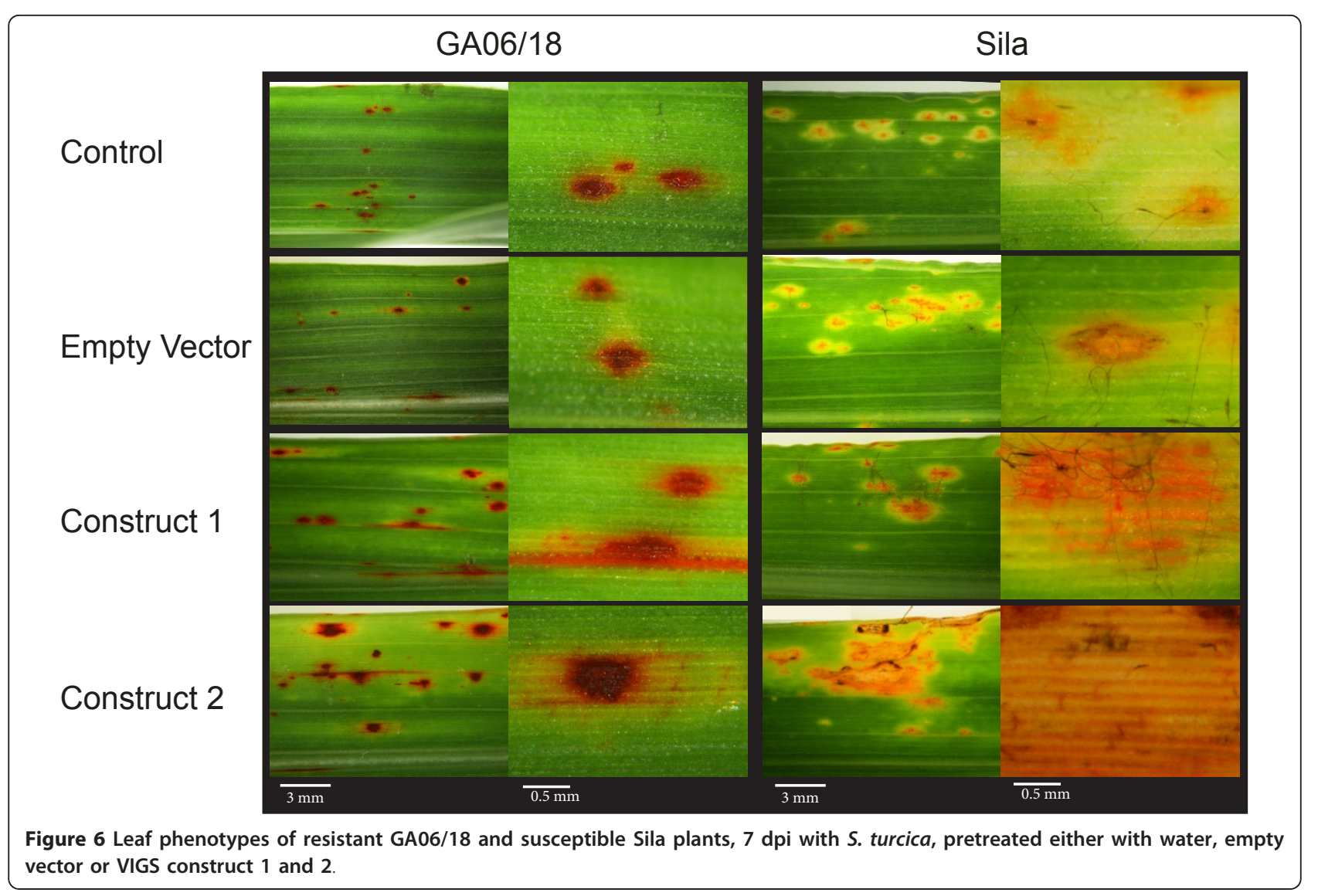

disease symptoms occurred 2 dpi. In contrast, on Sila plants inoculated with our VIGS construct 1, slightly larger and more frequent lesions appeared compared to control plants. The disease symptoms were further amplified when construct 2 was used, resulting in larger necrotic lesions, and profuse fungal sporulation. In order to correlate these observed disease phenotypes with fungal growth, fungal DNA was quantified in the VIGS materials (Figure 7). S. turcica DNA increased to $1.5 \pm 0.4 \mathrm{pg} / \mathrm{ng}$ sorghum DNA in GA06/18 leaves inoculated with VIGS construct 1 , and to $3.6 \pm 0.9 \mathrm{pg} /$ ng sorghum DNA when using construct 2, from a near zero level in control plants (non-VIGS and empty vector). A significant $(P<0.005)$ increase in fungal DNA was also found in samples from Sila inoculated with construct $1(1.2 \pm 0.4 \mathrm{pg} / \mathrm{ng}$ sorghum DNA), and construct $2(0.8 \pm 0.9 \mathrm{pg} / \mathrm{ng}$ sorghum DNA $)$, compared to control samples with approximately $0.5 \mathrm{pg} / \mathrm{ng}$ sorghum DNA.

Taken together, as expected the resistant GA06/18 genotype showed a compromised defense response when inoculated with VIGS construct 1 or 2 prior fungal inoculation. Interestingly, we observed enhanced disease phenotypes on the susceptible Sila genotype upon corresponding VIGS treatments.

\section{Discussion}

Sorghum [Sorghum bicolor (L.) Moench] serves as a major food staple and fodder resource especially in arid and semi-arid regions of the world [32]. It is mainly a self-pollinating and diploid grass species $(2 \mathrm{n}=2 \mathrm{x}=20)$, with a genome size of $1 \mathrm{C}=730 \mathrm{Mbp}$, which is about $25 \%$ the size of the maize genome $[4,5]$. In the sorghum genome, 211 NB-LRR encoding $R$-genes are present, which is approximately half the number found in rice and slightly more compared to Arabidopsis [4]. The number of NB-LRR encoding genes in the small genome of the wild grass Brachypodium is estimated to 178 [6]. But in the much larger maize genome, 95 NB-LRR encoding genes have up to now been identified [33]. However, depending on search programs and threshold settings, slightly different $R$-gene numbers in each grass species are published.

It is postulated that the high numbers of $R$-genes in plant genomes and their large sequence diversity are essential evolutionary factors in the surveillance machinery to resist pathogen attacks. Resistance genes evolve through duplication, unequal crossing over, recombination and diversification leading to clusters of paralogous genes [10,34]. The proliferation of $R$-genes is also coupled with rapid turnover of gene copies, eventually 


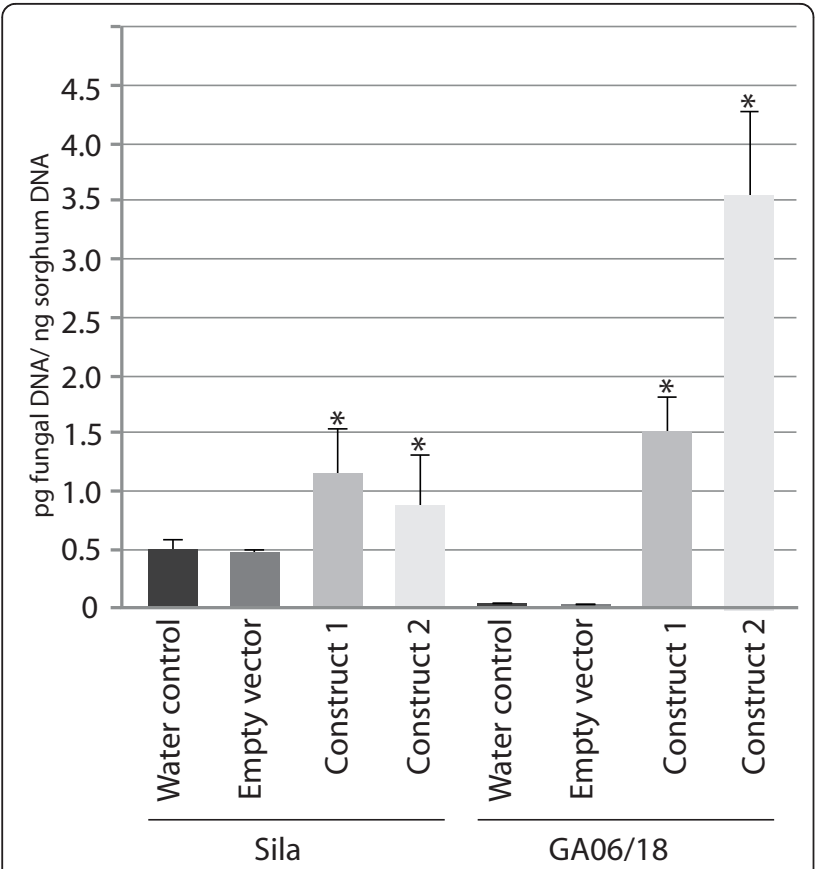

Figure 7 Real-time qPCR assessment of $S$. turcica DNA on resistant GA06/18 and susceptible Sila leaf samples, $7 \mathrm{dpi}$ with S. turcica, pretreated either with water, empty vector, or VIGS construct 1 and 2 . Error bars indicate standard deviation between three biological replications. ${ }^{*}$ Indicates a significant increase $(P<$ 0.05) in fungal DNA compared to control levels.

leading to deletion or expansion and thus dynamic $R$ gene clusters [33]. Resistance gene clusters have also been found to be conserved between different species in Poaceae [35], although, such clusters are in the minority with $71.6 \%$ being specific to a species [33].

Whole genome duplications occurred when the grass subfamilies diverged from each other and genome data suggest further, that paleo-duplicated gene pairs in sorghum and rice remained extant in about $17 \%$ of the cases [36]. Recent duplications of chromosomal segments are particularly found on rice chromosomes 11 and 12, and corresponding regions on chromosome 5 and 8 in sorghum. Chromosome 5, in the sequenced BTx623 sorghum genotype, where the $S t$ genes are located showed the highest abundance (62) of $R$-genes [4]. Thirty-six of these NB-LRR encoding genes are affected by recent duplication events based on the bioinformatic analyses presented by Wang et al. [36], including St $3 A$ and $S t 3 B$, which is in agreement with our results (Figure 1; Additional file 2). Interestingly, the rice genome contains orthologs of St1A, St1B, St $2 A, S t 2 B$ and a single ortholog of the $S t 3$ genes, all in one single locus. This indicates that this gene cluster predates the species split of rice and sorghum. In the grass family, sorghum, maize and millets belong to the same sub-family (Panicoideae), whereas rice is located in Ehrhartoideae [37]. It is estimated that these two subfamilies diverged from a common ancestor 50-70 million years ago together with Pooideae, the subfamily to which Brachypodium, wheat, and barley belong.

In a genome-wide comparison of Arabidopsis thaliana and $A$. lyrata, the evolutionary pattern of the $R$-genes could be divided into two distinct groups, the positively selected $(>50 \%)$ with high sequence divergence between the two species, or the stably selected genes $(<30 \%)$ [38]. The remaining genes were only found in one genome and absent from the other. The St genes found in this work have experienced few sequence exchanges resulting in low divergence, and hence more resemble the description of stably selected genes, although the copy numbers vary between the five grass genomes compared (Figure 1). That NB-LRR encoded $R$-genes remain conserved between different grass species is presently believed to be a common phenomenon [33].

Sorghum plants, particularly genotypes with red seed color, accumulate a range of phenolic substances in response to pathogen attacks [39]. Large amounts of redpigmented flavonoids induced at the site of infection were also seen in our materials, particularly in the resistant genotype. Whether flavonoids contribute to the defense response against $S$. turcica is not elucidated but a genetic link has been found in the sorghum - C. sublineolum interaction, produced via the presence of 3-deoxyanthocyanidins [40]. Reinforcement of plant cells via callose deposition upon pathogen attacks have been observed in many pathosystems. Enhanced callose deposition has also been reported as a resistance response to $S$. turcica in maize [41]. Despite extensive staining efforts, no callose accumulation was seen in either of our sorghum genotypes (data not shown).

Furthermore, our gene silencing work resulted in an enhanced susceptible response in Sila, our susceptible sorghum cultivar. This observation may suggest that by targeting the $S t$ genes in this genomic background, effects on downstream signaling masked in the resistant sorghum genotype are revealed, and could potentially constitute a fraction of the quantitative traits earlier found [41]. This hypothesis is speculative and remains to be included in future functional studies of the $S t$ genes. Future studies do also comprise a search for important effectors in the genome recently released from JGI http://www.jgi.doe.gov. In parallel, the sequence information from the St gene cluster is presently converted into molecular markers and used in germplasm assessments and breeding programs in East Africa, an important development to sustain sorghum and maize crop production in this part of the world.

\section{Conclusions}

Our cDNA-AFLP analysis on susceptible and resistance maize and sorghum genotypes challenged by $S$. turcica 
resulted in identification of a CC-NB-LRR encoding gene in maize. This gene resides in two loci on maize chromosome 2. In sorghum, $6 \mathrm{St}$ orthologous genes are present in a cluster of three pairs, on chromosome 5 . Upon gene-silencing of the sorghum $S t$ genes, the resistance was clearly compromised, an observation that was supported by real-time PCR analysis and fungal DNA quantification. Database searches and phylogenetic analysis suggest that the St genes have a common ancestor present before the subfamily split, 50-70 million years ago, and the genes are highly conserved in sorghum, rice, foxtail millet, maize and Brachypodium.

\section{Methods}

\section{Plant and fungal materials}

Resistant (R) and susceptible (S) Sorghum bicolor genotypes from Uganda, GA06/18 (R) and Sila (S), and maize lines A619Ht1 (R) and A619 (S) provided by USDA ARS, were used in the study. The plants were grown in a growth chamber (Percival) using a $12 / 12 \mathrm{~h}$ photoperiod at $22^{\circ} \mathrm{C}$. A single spore isolate from $S$. turcica infected sorghum (Ig1), or infected maize $(M b 1)$, collected from Iganga and Mbale, Uganda, was used for all sorghum and maize analysis, respectively. The fungal DNA was extracted using a modified CTAB method [42]. DNA was analyzed by using S. turcica specific ITS1 and ITS2 primers (F - GCAACAGTGCTCTGCTGAAA and R-ATAAGACGGCCAACACCAAG). PCR was carried out using the following conditions: $10 \mathrm{ng}$ of template DNA was added to a $24 \mu \mathrm{l}$ mix consisting of $\mathrm{H}_{2} \mathrm{O}, 2.5 \mathrm{mM} \mathrm{MgCl}, 2.5 \mu \mathrm{l}$ Taq buffer (Fermentas, Helsingborg, Sweden) $0.2 \mathrm{mM}$ of each dNTP, $0.25 \mu \mathrm{M}$ of forward and reverse primers and $1 \mathrm{U}$ of Taq polymerase (Fermentas) with: $3 \mathrm{~min}$ at $94^{\circ} \mathrm{C}, 35$ cycles of $\left(1 \mathrm{~min}\right.$ at $94^{\circ} \mathrm{C}, 1 \mathrm{~min}$ at $60^{\circ} \mathrm{C}$, and $1.5 \mathrm{~min}$ at $72^{\circ} \mathrm{C}$ ), and final extension at $72^{\circ} \mathrm{C}$ for $10 \mathrm{~min}$. The PCR products were separated on $1 \%$ agarose gels to confirm fragment size, (344 bp) followed by sequencing (Macrogen Inc., Seoul, Korea).

\section{Fungal inoculation of plant material}

Three-week old seedlings were inoculated on the third leaf whorl with $25 \mu$ l conidia suspension $\left(5 \times 10^{5}\right.$ conidia $\left./ \mathrm{ml}\right)$ as described by Carson [43]. Inoculated leaves from three to four plants were pooled and harvested at 24,48 , and 78 hours post inoculation (hpi) for cDNA-AFLP analysis. Water treated control samples were harvested at the same time-points.

\section{RNA extraction and CDNA-AFLP analysis}

Total RNA was isolated from the leaf samples using the BioRad RNA isolation kit (BioRad, California, USA) followed by mRNA preparation with the mRNA capture kit (Roche, California, USA). cDNA was synthesized with Oligo-dT primer and RevertAid ${ }^{\mathrm{TM}} \mathrm{H}$ Minus M-MuLV
Reverse Transcriptase (Fermentas). Second strand was synthesized using E. coli DNA Polymerase I (Fermentas). The double stranded cDNA was digested with BstY1 and Mse 1 (Fermentas) and ligated to respective adaptors, preamplified and later selectively amplified using the BstYI $+\mathrm{N}\left({ }^{33} \mathrm{P}\right.$ labeled $)$ and $M s e \mathrm{I}+\mathrm{N}$ primers. Pre-amplification was carried out with the adapter-ligated cDNA, Taq DNA Polymerase (Fermentas) and the non-selective primers specific to the Bst YI and MseI adapters using 25 cycles of $94^{\circ} \mathrm{C}$ for $30 \mathrm{~s} ; 56^{\circ} \mathrm{C}$ for $1 \mathrm{~min}$ and $72^{\circ} \mathrm{C}$ for $1 \mathrm{~min}$. The pre-amplified reaction mixture was diluted 600 -fold and $5 \mu \mathrm{l}$ was used for final selective amplification with 24 primer combinations, carried out with BstYI $+\mathrm{N}\left({ }^{33} \mathrm{P}\right.$ labeled) primers (Additional file 1 ) and touchdown amplification [44]. The selective amplification products were resolved on $6 \%$ polyacrimide gel run at $100 \mathrm{~W}$ until $4300 \mathrm{Vh}$ was reached. Gels were dried and exposed to Kodak Biomax film (Amersham Pharmacia, California, USA) for 5-7 days.

\section{Isolation and sequencing of transcripts}

Approximately 150 transcripts (unique, up and downregulated) from the resistant genotypes in relation to the susceptible genotypes, were excised from the dried PAGE gels, eluted in $\mathrm{H}_{2} \mathrm{O}$ and PCR amplified using the nonselective primers under the same conditions as earlier described in the pre-amplification step. The products were cloned into the pJET 1.2 blunt vector (CloneJET ${ }^{\mathrm{TM}}$ PC, Fermentas) and sequenced. The sequences were analyzed using the BLASTN and BLASTX programs [45] and compared with sequences deposited in NCBI, GRAMENE and PHYTOZOME databases. Identified fungal sequences were excluded.

\section{Virus induced gene silencing (VIGS) in sorghum}

The VIGS system used is based on the monocot-infecting Brome mosaic virus (BMV) as previously described [30] but pre-inoculation on barley was excluded. The BMV VIGS vector consists of three plasmids harboring BMV RNA1 (p1-1), RNA2 (p2-2) and RNA3 (pF13m, formally pF3-5/13 $\mathrm{A} / \mathrm{G}$ ), respectively. To generate VIGS constructs, PCR fragments ranging from 246 to $253 \mathrm{bp}$ in size were amplified from the sorghum candidate gene using genomic DNA of the resistant GA06/18 genotype and genespecific primers harboring $N c o$ I and $A v r I I$ restriction sites using the Primer 3 version 0.4.0 http://frodo.wi.mit. edu/primer3/ software (Additional file 6). Prior to PCR amplification, off-target gene searches were undertaken to design optimal VIGS constructs (Figure 4). After restriction, each fragment was cloned into the corresponding site of the pF13m plasmid. The identity of the inserts was verified by sequencing. P1-1, p2-2 and the pF13m containing different constructs were digested with SpeI, PshAI and PshAI, respectively. Infectious RNA 
transcripts were synthesized from linearized plasmids through in vitro transcription using T3 Polymerase (Fermentas), according to manufacturer instructions. $1 \mu \mathrm{l}$ of the reaction product was run on a $1.5 \%$ agarose gel to confirm presence of a transcript.

Plant inoculation procedures were performed as described [30] with slight modifications. A $10 \mu \mathrm{l}$ aliquot of the transcription mix from each of the plasmids p1-1, p22 and pF13m-insert was combined with $30 \mu \mathrm{FES}$ inoculation buffer and used directly to rub inoculate the second and third leaves of 3-week-old sorghum and maize plants. As a control, plants were inoculated in the same way with water or combined transcripts from p1-1, p2-2 and empty pF13m. Maize and sorghum plants were challenged with S. turcica as earlier described one week after viral inoculation (when faint chlorosis and vein clearing started to appear) to assess the effect of the different constructs. Plants were randomized and coded to reduce potential bias in the scoring of fungal colonization and growth.

\section{Quantitative real-time PCR}

Prior to fungal inoculation of the VIGS treated sorghum plants, approximated $3 \mathrm{~cm}$ of the second leaf above the VIGS inoculated leaf was collected from 3 independent plants in triplicates for each condition and used for RNA extraction as previously described. First strand-cDNA was synthesized from $1 \mu \mathrm{g}$ of total RNA, with Oligo-dT primer and RevertAid ${ }^{\mathrm{TM}} \mathrm{H}$ Minus M-MuLV Reverse Transcriptase (Fermentas) according to the manufacturer's instructions. Real-time PCR was carried out using the first strand cDNA in an iQ5 cycler (Bio-Rad). Maxima Sybr Green/ Fluorescein qPCR Master Mix (Fermentas) was used for PCR amplification in a $20 \mu \mathrm{l}$ total reaction volume consisting of $10 \mu \mathrm{l}$ of SYBR Green qPCR Master Mix, $0.3 \mu \mathrm{M}$ forward and reverse primers and 5 ng of cDNA template. All PCRs were performed in triplicate under the following amplification conditions; $10 \mathrm{~min}$ at $95^{\circ} \mathrm{C}$ followed by 40 cycles of $95^{\circ} \mathrm{C}$, for $15 \mathrm{~s}, 60^{\circ} \mathrm{C}$ for $30 \mathrm{~s}$, and $72^{\circ} \mathrm{C}$ for $30 \mathrm{~s}$, followed $1 \mathrm{~min}$ at $95^{\circ} \mathrm{C}$, and melt curve analysis. Primers sequences for $S t$ genes were designed using the Primer 3 version 0.4.0 http://frodo.wi.mit.edu/primer3/ software (Additional file 7). The sorghum elongation factor 1-alpha (Sb02g036420) and Actin (Sb01g010030) were used as reference genes and relative transcript values were calculated. All calculations and statistical analyses were performed as described in the ABI PRISM 7700 Sequence Detection System User Bulletin \#2 (Applied Biosystems, USA) slightly modified by Vetukuri et al. [46]. Quantification of S. turcica DNA on VIGS material 7 days post fungal inoculation was carried out as earlier described [41]. Approximately $3 \mathrm{~cm}$ of leaf material from three plants was pooled and DNA extracted. Three biological samples per treatment were analyzed. Statistical significance was calculated using Student's t-test.

\section{Genome analysis}

The amino acid sequences of St1A (Sb05g008280), St1B (Sb05g008140), St2A (Sb05g008350), St2B (Sb05g008030), St3A (Sb05g008250) and St3B (Sb05g008270) were aligned to sorghum, maize, millet, rice, Brachypodium and Arabidopsis genome databases using BLASTN and BLASTP (PHYTOZOME). Predicted domains were identified using coiled-coil prediction [47]), LRRfinder [48] and CD-Search [49]. St-like gene loci were identified using Genomic Viewer (PHYTOZOME). Phylogenetic analysis was conducted using Treefinder and maximum likelihood and 10, 000 replicates [50]. The JTT+G model [51] was found to best fit the data using ProtTest v2.4 [52]. Confidences were calculated using local rearrangement of expected likelihood weights (LR-ELW) [53]. Phylograms were drawn using Treeview 1.6.6 [54].

\section{Additional material}

Additional file 1: PCR primer combinations used in CDNA-AFLP
analysis.

Additional file 2: Maximum likelihood phylogenetic tree using the model JTT+G based on amino acid sequence from the coiled coil (CC), nucleotide binding (NB) and leucine rich repeat (LRR) domains of St proteins in sorghum, and closely related $\mathbf{R}$ proteins. Names refer to PHYTOSOME gene identifier. Physcomitrella patens $R$-protein Pp1s1_327V6, was used as an out-group. LR-ELW edge support values are shown [53]. Substitutions per site are indicated.

Additional file 3: Information on genes used in Figure 1 and their putative function. Data retrieved from the PHYTOSOME database. GenBank accession numbers are stated where present.

Additional file 4: Information on Arabidopsis genes used in Figure 3. Data retrieved from the TAIR database.

Additional file 5: Disease phenotypes on sorghum leaves, monitored 1-12 days post inoculation (dpi) with $S$. turcica on the resistant wild type GA06/18 and the susceptible Sila cultivar. The plants were treated with either water, empty BMV vector, construct 1 or construct 2, prior to fungal inoculation. The data is compiled from 25-30 plants per BMV construct and controls. The experiment was repeated 2 times.

Additional file 6: Gene specific primers for VIGS constructs. Restriction sites are in bold.

Additional file 7: List of primers used in real time PCR analysis.

\section{Acknowledgements}

We greatly acknowledge B. Sarosh for assisting with the CDNA-AFLP work. This study was funded by the SIDA-SAREC grant for the East African Biotechnology Network (BIO-EARN), Sida SWE-2005-453, and the Swedish University of Agricultural Sciences.

\section{Author details}

${ }^{1}$ SLU, Uppsala Biocenter, Dept. Plant Biology and Forest Genetics, Uppsala P. O. Box 7080, S-750 07, Uppsala, Sweden. ${ }^{2}$ Dept. of Crop Science, Makerere University P.O. Box 7062, Kampala, Uganda. ${ }^{3}$ National Agriculture Research Organisation, P.O. Box 295, Entebbe, Uganda.

\section{Authors' contributions}

TM carried out the GPCR, genomic analysis, created figures, and ran the CDNA-AFLP and VIGS analyses together with MB. IF supported on the VIGS analysis. CD and PO conceived the study and participated in writing 
together with all authors. All authors read and approved the final manuscript.

Received: 3 June 2011 Accepted: 3 November 2011

Published: 3 November 2011

\section{References}

1. Jones JDG, Dangl J: The plant immune system. Nature 2006, 444(7117):323-329.

2. Meyers BC, Kozik A, Griego A, Kuang H, Michelmore RW: Genome-wide analysis of NB-LRR-encoding genes in Arabidopsis. Plant Cell 2003, 15(4):809-834.

3. Liu J, Liu X, Dai L, Wang G: Recent progress in elucidating the structure, function and evolution of disease resistance genes in plants. Journal of Genetics \& Genomics 2007, 34(9):765-776.

4. Paterson AH, Bowers JE, Bruggmann $\mathrm{R}$, et al: The Sorghum bicolor genome and the diversification of grasses. Nature 2009, 457(7229):551-556.

5. Schnable PS, Ware D, Fulton RS, et al: The B73 maize genome: complexity, diversity and dynamics. Science 2009, 326(5956):1112-1115.

6. The International Brachypodium Initiative: Genome sequence and analysis of the model grass Brachypodium distachyon. Nature 2010, 463(7282):763-768

7. Collier SM, Moffett P: NB-LRRs work a "bait and switch" on pathogens. Trends in Plant Science 2009, 14(10):521-529.

8. Smith SM, Pryor AJ, Hurlbert SH: Allelic and haplotypic diversity at the $r p 1$ rust resistance locus of maize. Genetics 2004, 167(4):1939-1949.

9. Kuang H, Woo S-S, Meyers BC, Nevo E, Michelmore RW: Multiple genetic processes result in heterogeneous rates of evolution within the major cluster disease resistance genes in lettuce. Plant Cell 2004, 16(11):2870-2894.

10. McDowell JM, Simon SA: Recent insights into $R$ gene evolution. Molecular Plant Patholology 2006, 7(5):437-448.

11. Dixon MS, Jones DA, Keddie JS, Thomas CM, Harrison K, Jones JDG: The tomato $C f-2$ disease resistance locus comprises two functional genes encoding leucine-rich repeat proteins. Cell 1996, 84(3):451-459.

12. Eitas TK, Dangl JL: NB-LRR proteins: pairs, pieces, perception, partners and pathways. Current Opinion in Plant Biology 2010, 13(4):472-477.

13. Hamid A, Aragaki M: Inheritance of pathogenicity in Setosphaeria turcica. Phytopathology 1975, 65(3):280-283.

14. Chiang M, van Dyke C, Leonard K: Evaluation of endemic fungi for potential biological control of Johansongrass (Sorghum halepense): Screening and host range tests. Plant Disease 1989, 73(6):459-464.

15. Perkins JM, Pedersen WL: Disease development and yield losses associated with northern leaf blight on corn. Plant Disease 1987, 71(10):940-943.

16. Carson $\mathrm{ML}$, van Dyke C: Effect of light and temperature on expression of partial resistance of maize to Exserohilum turcicum. Plant Disease 1994, 78(4):408-411

17. Pratt R, Gordon S: Breeding for resistance to maize foliar pathogens. Plant Breeding Reviews 2006, 27:119-173.

18. Welz G, Geiger H: Genes for resistance to northern corn leaf blight in diverse maize populations. Plant Breeding 2000, 119(1):1-14.

19. Mangelsdorf PC: Corn: its origin, evolution and improvement. Belknap Press, Cambridge, Mass. USA; 1974.

20. Kimber CT: Origins of domesticated sorghum and its early diffusion into India and China. In Sorghum: origin, history, technology and production. Edited by: Smith CW, Frederiksen RA. John Wiley 2000:3-98.

21. Ngugi HK, King SB, Holt J, Julian AM: Simultaneous temporal progress of sorghum anthracnose and leaf blight in crop mixtures with disparate patterns. Phytopathology 2001, 91(8):720-729.

22. Adipala E, Lipps EP, Madden LV: Occurrence of Exserohilum turcicum on maize in Uganda. Plant Disease 1993, 77(1):202-205.

23. Ebiyau J, Oryokot OE: Sorghum (Sorghum bicolor (L.) Moench. Agriculture in Uganda. Crops: National Agricultural Research Organisation Fountain Publ; 2001II.

24. Muiru WM: Histological studies and characterization of races of Exserohilum turcicum the causal maize agent of northern leaf blight of maize in Kenya. PhD thesis University of Nairobi, Kenya; 2008.

25. Ramathani I: Characterisation of turcicum leaf blight epidemics and pathogen populations in the Exserohilum turcicum - Sorghum pathosystem in Uganda. MSc thesis Makerere Univ. Kampala, Uganda; 2009.
26. Ramathani I, Biruma M, Martin T, Dixelius C, Okori P: Disease severity, incidence and races of Setosphaeria turcica on sorghum in Uganda. European Journal of Plant Pathology 2011, 131(3):383-392.

27. Grant MR, Godiardt L, Straube S, Ashfield T, Lewald J, Satler A, Ines RW, Dangl $\mathrm{J}$ : Structure of the RPM1 gene enabling dual specificity disease resistance. Science 1995, 269(5225):843-846.

28. Opabode J: Agrobacterium-mediated transformation of plants: emerging factors that influence efficiency. Biotechnology and Molecular Biology Reviews 2006, 1(1):12-20.

29. Gurel S, Gurel E, Kaur R, Wong J, Meng L, Tan HQ, Lemaux PG: Efficient, reproducible Agrobacterium-mediated transformation of sorghum using heat treatment of immature embryos. Plant Cell Reports 2009, 28(3):429-444.

30. Ding XS, Schneider WL, Chaluvadi SR, Mian MAR, Nelson RS: Characterization of a Brome mosaic virus strain and its use as vector for gene silencing in monocotyledonous hosts. Molecular Plant-Microbe Interactions 2006, 19(11):1229-1239.

31. Levy $Y$ : Variation of fitness among field isolates of Exserohilum turcicum in Israel. Plant Disease 1991, 75(2):163-166.

32. Doggett H: Sorghum. John Wiley, New York, US; 21988.

33. Li J, Ding J, Zhang Y, Wang J, Chen J-Q, Tian D, Yang S: Unique evolutionary pattern of numbers of gramineous NBS-LRR genes. Molelucar Genetics \& Genomics 2010, 283(5):427-438.

34. Meyers BC, Kaushik S, Nandety RS: Evolving disease resistance genes. Current Opinion in Plant Biology 2005, 8(2):129-134.

35. Luo S, Peng J, Li K, Wang M, Kuang H: Contrasting Evolutionary patterns of the $R p 1$ resistance gene family in different species of Poaceae. Molecular Biology \& Evolution 2011, 28(1):313-325.

36. Wang $X$, Wang $H$, Paterson AH: Seventy million years of concerted evolution of a homoeologous chromosome pair, in parallel, in major Poaceae lineages. Plant Cell 2011, 23(1):27-37.

37. Bolot S, Abrouk M, Masood-Quraishi U, Stein N, Messing J, Feuillet C, Salse J: The inner circle of the cereal genomes. Current Opinion in Plant Biology 2009, 12(2):119-125.

38. Chen Q, Han Z, Jiang H, Tian D, Yang S: Strong positive selection drives rapid diversification of $R$-genes in Arabidopsis relatives. Journal of Molecular Evolution 2010, 70(2):137-148.

39. Dicko MH, Gruppen H, Barro C, Traore AS, van Berkel WJH, Voragn AGJ: Impact of phenolic compounds and related enzymes in sorghum varieties for resistance and susceptibility to biotic and abiotc stresses. Journal of Chemical Ecology 2005, 31(11):2671-2687.

40. Ibraheem F, Gaffoor I, Chopra S: Phytoalexin-dependent resistance to anthracnose leaf blight requires a functional yellow seed 1 in Sorghum bicolor. Genetics 2010, 184(4):915-926.

41. Chung C-L, Longfellow JM, Walsh EK, Kerdieh Z, van Esbroeck G, BalintKurti P, Nelson RJ: Resistance loci affecting distinct stages of fungal pathogenesis: use of introgression lines for QTL mapping and characterization in the maize-Setosphaeria turcica pathosystem. BMC Plant Biology 2010, 10:103.

42. Okori P, Rubaihayo PR, Ekwamu A, Fahleson J, Dixelius C: Genetic characterization of Cercospora sorghi from cultivated and wild sorghum and its relationship to other Cercospora fungi. Phytopathology 2004, 94(7):743-750.

43. Calsson ML: Inheritance of latent period length in maize infected with Exserohilum turcicum. Plant Disease 1995, 79(6):581-585.

44. Vos $P$, Hogers $R$, Bleeker M, Reijans M, Vandelee $T$, Hornes M, Frijters $A$, Pot J, Peleman J, Kuiper M, Zabeau M: AFLP a new technique for DNA fingerprinting. Nucleic Acids Research 1995, 23(21):4407-4414.

45. Altschul SF, Gish W, Miller W, Myers EW, Lipman DJ: Basic local alignment search tool. Journal of Molecular Biology 1990, 215(3):403-410.

46. Vetukuri RR, Avrova AO, Grenville-Briggs $\amalg$, van West $P$, Söderbom F, Savenkov El, Whisson SE, Dixelius C: Evidence for involvement of Dicerlike, Argonaute, and Histone Deacetylase proteins in gene silencing in Phytophthora infestans. Molecular Plant Pathology 2011, 12(8):772-785.

47. Lupas A, Van Dyke M, Stock J: Predicting coiled coils from protein sequences. Science 1991, 252(5010):1162-1164.

48. Offord V, Coffey TJ, Werling D: LRRfinder: a web application for the identification of leucine-rich repeats and an integrative Toll-like receptor database. Development \& Comparative Immunology 2010, 34(10):1035-1041.

49. Marchler-Bauer A, Bryant SH: CD-Search: protein domain annotations on the fly. Nucleic Acids Research 2004, 32:W327-331. 
50. Jobb G, von Haeseler A, Strimmer K: TREEFINDER: a powerful graphical analysis environment for molecular phylogenetics. BMC Evolutionary Biology 2004, 4:18.

51. Jones DT, Taylor WR, Thornton JM: The rapid generation of mutation data matrices from protein sequences. Computer Applications in the Biosciences 1992, 8(3):275-282.

52. Abascal F, Zardoya R, Posada D: ProtTest: selection of best-fit models of protein evolution. Bioinformatics 2005, 21(9):2104-2105.

53. Strimmer K, Rambaut A: Inferring confidence sets of possibly misspecified gene trees. Proceedings of the Royal Society B: Biological Sciences 2002, 269(1487):137-142

54. Page RD: TreeView: an application to display phylogenetic trees on personal computers. Computer Applications in Biosciences 1996 12(4):357-358.

55. Bowman J, Floud S, Sakakibara K: Green genes - comparative genomics of the green branch of life. Cell 2007, 129(2):229-234.

doi:10.1186/1471-2229-11-151

Cite this article as: Martin et al: A highly conserved NB-LRR encoding gene cluster effective against Setosphaeria turcica in sorghum. BMC Plant Biology 2011 11:151.

\section{Submit your next manuscript to BioMed Central} and take full advantage of:

- Convenient online submission

- Thorough peer review

- No space constraints or color figure charges

- Immediate publication on acceptance

- Inclusion in PubMed, CAS, Scopus and Google Scholar

- Research which is freely available for redistribution

Submit your manuscript at www.biomedcentral.com/submit 